\title{
The role of research in the failure of the alcopops excise in Australia: what have we learned?
}

\author{
Anthony Shakeshaft, Christopher M Doran and Joshua Byrnes
}

L egislation ratifying the Australian Government's April 2008 move to equalise the excise applied to straight spirits and premixed spirits ("alcopops") was blocked in the Senate on 18 March 2009 by a single vote, ostensibly the result of the government's failure to reach an agreement with an independent senator. Although the political process, including intense lobbying by various industry groups, was no doubt an important contributor, the demise of the legislation also raises the troubling question of why research evidence left so much room for political manoeuvring on legislation designed to reduce the negative impact of alcohol - the most widely used and easily the second most harmful drug (after tobacco) in Australia. ${ }^{1}$

The possibility that there was insufficient scope to present research evidence is not convincing. Two inquiries were held by the Senate Community Affairs Committee, accepting submissions from a range of interest groups. The first inquiry, held in June 2008, supported a number of propositions: that binge drinking imposes a substantial burden of harm, to which young people are particularly vulnerable; that premixed spirit drinks are a preferred beverage of young people; and that price is an appropriate public health policy lever. ${ }^{2}$ Subsequent to this hearing, peer-reviewed articles provided further support for the alcopops excise policy initiative, while raising concerns about the likely effectiveness of implementing only a single strategy., ${ }^{3,4}$ The second inquiry, held in March 2009, provided an opportunity to present evidence regarding the effectiveness of the alcopops tax on binge drinking among young people, after it had been in place for 12 months. This time, however, the research presented was largely equivocal and essentially limited to data from the Australian Taxation Office, market research companies and hospitals. ${ }^{5}$

The excessive room for political manoeuvring is more likely to reflect a lack of relevant research evidence, rather than a lack of opportunity to present the evidence in an appropriate forum. No adequately reliable and valid data specific to the effect of the increase in alcopops excise on youth binge drinking (either its frequency or severity per occasion) and its associated harms were presented to these inquiries, despite recognition for at least 20 years that as much as two-thirds of alcohol-related harm in Australia is attributable to accidents, injuries and misuse of alcohol associated with drinking to intoxication. ${ }^{6,7}$

The critical point - that currently available alcohol data are insufficiently specific, reliable and valid to allow adequate judgement of the effectiveness of population-level interventions and public policy - can be illustrated by briefly reviewing the alcopops tax in Australia. In 2000, a new tariff was applied to all alcoholic beverages not exceeding $10 \%$ strength by volume that were not already covered elsewhere (eg, beer and wine), to remove ambiguity in the excise rate for spirits sold as alcopops (less than $10 \%$ strength by volume) compared with straight spirits (more than $10 \%$ strength by volume). Relative to straight spirits, this new tariff represented a $40 \%$ tax discount in favour of alcopops (\$33.22 per litre compared with $\$ 56.27$ ). As this tax

\section{ABSTRACT}

- We believe that a lack of adequate alcohol measures research is partly responsible for the failure of the Australian Government to pass legislation to equalise the excise applied to straight spirits and premixed spirits ("alcopops").

- Current measures only assess total alcohol consumption rather than patterns of consumption, and do not adequately identify alcohol-related harm at a population level.

- Possible solutions include making further efforts to develop applied community-level measures and responding to the repeated calls for national collection and analysis of alcohol sales data.

- With the Australian Government able to retain the alcopops excise raised to date, there is a unique opportunity for greater collaboration between researchers and government to ensure high-quality and publicly relevant research is funded and conducted to address the current lack of adequate measures research.

- Measures research is a priority, as this is the basis for increasing the accuracy of data with which more cost-effective public policy and initiatives can be formulated and evaluated.

- The challenge is for researchers and the Australian Government to align their expertise to ensure revenue from public taxes engenders measurable public health benefit.

MJA 2009; 191: 223-225

advantage was passed on to consumers, both the proportion of total alcohol expenditure (value) attributable to alcopops and their consumption (volume) tripled between 1999 and 2007, from $6.4 \%$ to $18.9 \%$ and $3.5 \%$ to $12.3 \%$, respectively. Alcopops arguably not only competed for market share but also increased the overall alcohol market. Between 1999 and 2007, total pure alcohol consumption in Australia increased from 9.69 to 10.31 litres per capita, ${ }^{8}$ while national survey data show that the proportion of people aged at least 14 years who reported consuming alcohol in the previous 12 months increased from $80.6 \%$ in 1998 to $82.9 \%$ in $2007 .{ }^{9}$

There are significant problems with these data, however, that should have been addressed in the 20 years since the high contribution that drinking to intoxication makes to alcohol-related harm was recognised. First, they are restricted to measures of total alcohol consumption rather than examining patterns of consumption - they take no account of the additional risks associated with drinking to intoxication.

Second, current measures do not directly measure harm, and it is not at all clear that an increase in consumption of alcopops per se will necessarily result in an increase in harm. For example, data from 5444 drinkers aged 13-16 years in Switzerland suggest that 
those who drink alcopops do not necessarily have riskier drinking patterns, nor more negative consequences than those who drink other alcoholic beverages. ${ }^{10}$ While it is obvious that the tax discount applied to alcopops has increased alcopop sales, it is at least arguable that it has also increased total alcohol consumption in Australia (by somewhere between 2\% ${ }^{9}$ and $6 \%^{8}$ ) and that alcohol-related harm has increased as a consequence of the increase in total consumption, not simply because the market share of alcopops has increased. In that case, public health policy should aim to reduce total alcohol consumption - for which current evidence indicates a volumetric tax (ie, based on the alcohol content) is the most cost-effective intervention ${ }^{11}$ - rather than focus on the relative contribution of different beverage types.

The troubled passage of the alcopops legislation in the Australian Parliament has three key implications: first, the quality of currently available alcohol measures needs improvement; second, data derived from improved measures should more effectively underpin and evaluate public policy; and third, more effective liaison needs to be established between researchers and governments to demonstrate the relevance and pragmatic role of measures in public policy.

The primary reason for the current lack of adequate measures is that establishing their reliability and validity has consistently comprised no more than $10 \%$ of relevant research effort since at least $1983,{ }^{12-14}$ and alcohol intervention trials persist with methodologically inadequate measures. ${ }^{13-15}$ Once reliable and valid measures are identified, particularly for alcohol-related harm, efforts will be required to ensure they are used routinely to monitor changes over time, including changes to public policy and public health initiatives.

This is not wild optimism. Collection of alcohol sales data, for which there have been repeated calls, ${ }^{16}$ would improve the methodological quality of current indicators of total alcohol consumption and would remove reliance on privately collected data that are expensive to access. ${ }^{8}$ Population-level measures of alcohol-related harm, as opposed to alcohol consumption, are emerging from community-level research efforts, such as the Alcohol Action in Rural Communities (AARC) trial. ${ }^{17}$ The graph shown in the Box applies surrogate measures used in the AARC trial to alcohol-related crime rates among young people (aged $\leqslant 25$ years) in New South Wales. Although requiring careful statistical analysis to be more definitive, it demonstrates the benefit of measuring alcohol-related harm: the $21 \%$ increase in alcoholrelated crime (from 4203 to 5077 incidents) after the alcopops tax increase (April to December 2008) is less than the 37\% increase (from 4593 to 6284 incidents) seen for the same time period before the alcopops tax (April to December 2007). Controlling for population growth shows increases of $23 \%$ for 2008 and $34 \%$ for 2007. With greater investment in measures research, similar indicators could be developed for a range of alcohol-related outcomes, including injuries and traffic accidents.

Increasing the accuracy of data, by improving the reliability and validity of the measures from which they derive, provides the potential for cost-effective public policy, in terms of its formulation and evaluation, as well as more rational distribution of resources. If, for example, improved data indicated the likely benefit of a public health goal that restricts total alcohol consumption, then demand-reduction strategies, such as a volumetric tax and mandatory advertising restrictions, are appropriate. If the benefit of

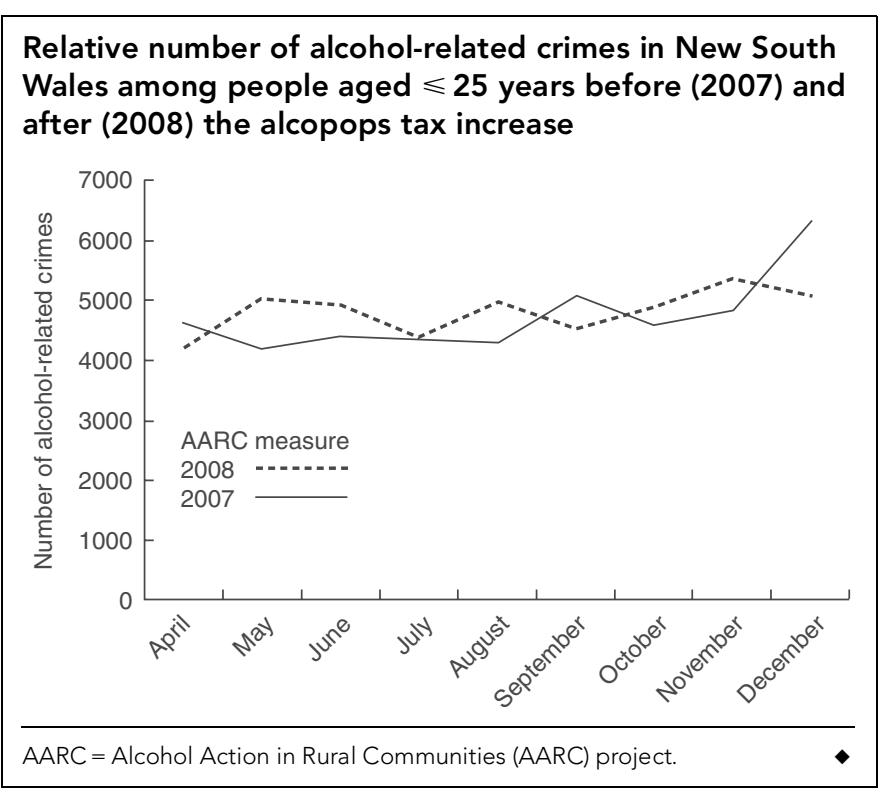

reducing accidents and injuries associated with drinking to intoxication is also indicated, additional supply and harm-reduction interventions targeting high-risk times and locations, such as earlier closing times and fewer alcohol outlets, would also be warranted. Whatever the interventions, improved measures would allow accurate evaluation of their effects.

Researchers, the medical profession, public health experts and others who are driven primarily by reducing alcohol-related harm, rather than by alcohol profit, can help realise the potential of improved measures by finding more effective ways of consulting and liaising with all levels of government. Although a difficult task, given competing priorities and goals, coherent effort between these groups is likely to ensure improved public health policy and more consistent public health messages for the community.

Again, a new era of mutually beneficial research and government collaboration is not fanciful. Funding for improved measures to design alcohol public policy and community initiatives and evaluate their cost-effectiveness could begin immediately, using a proportion of the alcopops excise already collected (the government's retention of which was facilitated by legislation passed on 12 May 2009). Using alcohol excise to fund innovative and pragmatic efforts to reduce alcohol-related harm is a principled approach that is likely to have strong community support.

The consequences of failing to address these issues are significant. A lack of reliable and valid data relevant to the alcopops excise policy, itself derived from insufficient consultation, left enough room for political manoeuvring to scuttle potentially effective legislation that was broadly supported by the public health community. Improved data and government liaison are two components of public policy development for which researchers can take greater responsibility. Achieving these will not in themselves result in more effective public policy, because such policy rightly derives from a broader political process that is beyond the scope of research. However, improving data and their usefulness to governments will make it more difficult for the broader political process to consistently hold sway, thus limiting, if not obviating, the opportunity for political manoeuvring. 


\section{Acknowledgements}

We thank Stephanie Love from the AARC project for generating the graph.

\section{Competing interests}

None identified.

\section{Author details}

Anthony Shakeshaft, PhD, Associate Professor and Assistant Director Christopher M Doran, PhD, Associate Professor and Assistant Director Joshua Byrnes, BEcon, PhD Candidate and Senior Research Officer National Drug and Alcohol Research Centre, University of New South Wales, Sydney, NSW.

Correspondence: a.shakeshaft@unsw.edu.au

\section{References}

1 Collins DJ, Lapsley HM. The costs of tobacco, alcohol and illicit drug abuse to Australian society in 2004/05. National Drug Strategy Monograph Series No. 64. Canberra: Commonwealth of Australia, 2008. http:// www.health.gov.au/internet/drugstrategy/publishing.nsf/Content/ mono64 (accessed Jun 2009).

2 Senate Community Affairs Committee. Inquiry into ready-to-drink alcohol beverages. Public hearings and transcripts. Jun 2008. http:// www.aph.gov.au/senate/committee/clac_ctte/alcohol_beverages/hearings (accessed Jun 2009).

3 Doran CM, Shakeshaft AP. Using taxes to curb drinking in Australia. Lancet 2008; 372: 701-702.

4 Chikritzhs TN, Dietze PM, Allsop SJ, et al. The "alcopops" tax: heading in the right direction [editorial]. Med J Aust 2009; 190: 294-295.

5 Senate Community Affairs Committee. Inquiry into Excise Tariff Amendment (2009 Measures No. 1) Bill 2009 and Customs Tariff Amendment (2009 Measures No. 1) Bill 2009 [provisions]. Public hearing and transcript. Mar 2009. http://www.aph.gov.au/senate/committee/clac_ctte/excise_ customs_tariff/hearings (accessed Jun 2009).
6 Begg S, Vos T, Barker B, et al. The burden of disease and injury in Australia 2003. Canberra: Australian Institute of Health and Welfare, 2007. (AlHW Cat. No. PHE 82.)

7 Kreitman N. Alcohol consumption and the preventive paradox. $\mathrm{Br} \mathrm{J}$ Addict 1986; 81: 353-363.

8 Euromonitor International. Alcoholic drinks in Australia. 2008. http:// www.euromonitor.com/Alcoholic_Drinks_in_Australia (accessed Apr 2008).

9 Australian Institute of Health and Welfare. 2007 National Drug Strategy Household Survey: detailed findings. Canberra: AlHW, 2008. (AlHW Cat. No. PHE 107.)

10 Wicki M, Gmel G, Kuntsche E, et al. Is alcopop consumption in Switzerland associated with riskier drinking patterns and more alcohol-related problems? Addiction 2006; 101: 522-533.

11 Cobiac L, Vos T, Doran CM, Wallace A. Cost-effectiveness of interventions to prevent alcohol-related disease and injury in Australia. Addiction 2009. In press.

12 Shakeshaft AP, Bowman JA, Sanson-Fisher RW. Behavioural alcohol research: new directions or more of the same? Addiction 1997; 92: 1411 1422.

13 Wood E, Shakeshaft A, Gilmour S, Sanson-Fisher R. A systematic review of school-based studies involving alcohol and the community. Aust NZ J Public Health 2006; 30: 541-549.

14 Webb G, Shakeshaft A, Sanson-Fisher R, Havard A. A systematic review of work-place interventions for alcohol-related problems. Addiction 2009; 104: 365-377.

15 Havard A, Shakeshaft A, Sanson-Fisher R. Systematic review and metaanalyses of strategies targeting alcohol problems in emergency departments: interventions reduce alcohol-related injuries. Addiction 2008; 103: 368-376

16 Hall WD, Chikritzhs TN, d'Abbs PH, Room RGW. Alcohol sales data are essential for good public policies towards alcohol [editorial]. Med J Aust 2008; 189: 188-189.

17 Petrie D, Doran C, Shakeshaft A, Sanson-Fisher R. The relationship between alcohol consumption and self-reported health status using the EQ5D: evidence from rural Australia. Soc Sci Med 2008; 67: 1717-1726.

(Received 5 Apr 2009, accepted 4 Jun 2009) 